University of Nebraska - Lincoln

DigitalCommons@University of Nebraska - Lincoln

2010

\title{
Female veterans of the OEF/OIF conflict: Concordance of PTSD symptoms and substance misuse
}

\author{
Sarah E. Nunnink \\ Veterans Affairs Center of Excellence for Stress and Mental Health \\ Gali Goldwaser \\ VA San Diego Healthcare System \\ Pia S. Heppner \\ Veterans Affairs Center of Excellence for Stress and Mental Health \\ James O.E. Pittman \\ Veterans Affairs Center of Excellence for Stress and Mental Health \\ Caroline M. Nievergelt \\ University of California - San Diego \\ See next page for additional authors
}

Follow this and additional works at: https://digitalcommons.unl.edu/publichealthresources

Part of the Public Health Commons

Nunnink, Sarah E.; Goldwaser, Gali; Heppner, Pia S.; Pittman, James O.E.; Nievergelt, Caroline M.; and Baker, Dewleen G., "Female veterans of the OEF/OIF conflict: Concordance of PTSD symptoms and substance misuse" (2010). Public Health Resources. 189.

https://digitalcommons.unl.edu/publichealthresources/189

This Article is brought to you for free and open access by the Public Health Resources at DigitalCommons@University of Nebraska - Lincoln. It has been accepted for inclusion in Public Health Resources by an authorized administrator of DigitalCommons@University of Nebraska - Lincoln. 


\section{Authors}

Sarah E. Nunnink, Gali Goldwaser, Pia S. Heppner, James O.E. Pittman, Caroline M. Nievergelt, and Dewleen G. Baker 


\title{
Female veterans of the OEF/OIF conflict: Concordance of PTSD symptoms and substance misuse
}

\author{
Sarah E. Nunnink ${ }^{\mathrm{a}, \mathrm{b}, \mathrm{c}, *}$, Gali Goldwaser ${ }^{\mathrm{b}}$, Pia S. Heppner ${ }^{\mathrm{a}, \mathrm{b}, \mathrm{c}}$, James O.E. Pittman ${ }^{\mathrm{a}, \mathrm{b}}$, \\ Caroline M. Nievergelt ${ }^{\mathrm{a}, \mathrm{c}}$, Dewleen G. Baker ${ }^{\mathrm{a}, \mathrm{b}, \mathrm{c}}$ \\ ${ }^{a}$ Veterans Affairs Center of Excellence for Stress and Mental Health, 3350 La Jolla Village Drive MC 116A, San Diego, CA 92161, United States \\ b VA San Diego Healthcare System, 3350 La Jolla Village Drive MC 116A, San Diego, CA 92161, United States \\ ' University of California, San Diego, Department of Psychiatry, 9500 Gillman Dr. MC 0603, San Diego, CA 92093-0603, United States
}

\section{A R T I C L E I N F O}

\section{Keywords:}

Female

Veteran

$\mathrm{OEF} / \mathrm{OIF}$

Alcohol

PTSD

Substance abuse

\begin{abstract}
A B S T R A C T
This study examined the post-deployment rates of comorbid PTSD and substance abuse in a cohort of female veterans who served in Operation Enduring Freedom and Operation Iraqi Freedom (OEF/OIF). Female OEF/ OIF veterans and reservists $(N=36)$ completed a battery of assessments as part of a larger study. Of the 36 participants, 11 (31\%) screened positive for posttraumatic stress disorder (PTSD), 17 (47\%) screened positive for high-risk drinking and $2(6 \%)$ screened positive for drug abuse. Higher scores on measures of alcohol and drug use predicted positive PTSD status $(p \leq 0.01)$ and alcohol misuse was significant in explaining unique variance of PTSD status $(p \leq 0.05)$. Our findings suggest a trend toward increased problematic drinking among female OEF/OIF veterans and reservists and a relationship between substance misuse and PTSD. Future research should investigate needs for gender-specific PTSD and substance-abuse treatment needs.
\end{abstract}

Published by Elsevier Ltd.

\section{Introduction}

Women currently make up $14.3 \%$ of the US military force (DOD, 2008) and $7.7 \%$ of the veteran population (DVA, 2007), and are recognized as a rapidly growing group (Goldberg, 2008; Romeis, Gillespie \& Thorman, 1988). Acknowledgement by the Department of Veterans Affairs (VA) that gender differences in mental health exist and have an impact on therapeutic provision is reflected in new policy encouraging gender-specialized care (Kussman, 2008). Since the recent Operation Enduring Freedom and Operation Iraqi Freedom (OEF/OIF) conflicts, the number of female veterans seeking care has never been higher (Goldberg, 2008), yet we know little about the post-deployment mental health status of this population. Historically, the health and mental health literature on veterans has centered on men, creating disparities in our knowledge of women (Davis, Bush, Kivlahan, Dobie \& Bradley, 2003; Goldzweig, Balekian, Rolon, Yano \& Shekelle, 2006)and a need to expand women veterans' health research (Yano, Bastian, Frayne, Howell, Lipson, McGlynn et al., 2006). Thus far, it appears that the OEF/OIF wars appear to be no exception to this trend. Importantly, the psychiatric status of the nation's female OEF/OIF veterans is an area in need of focused study, given that a limited body of research from the $\mathrm{OEF} / \mathrm{OIF}$ conflicts has documented that women were overly represented among those who had to be psychiatrically evacuated from the theater

\footnotetext{
* Corresponding author. Veterans Affairs Center of Excellence for Stress and Mental Health, 3350 La Jolla Village Drive MC 116A, San Diego, CA 92161, United States.

E-mail address: sarahnunnink@hotmail.com (S.E. Nunnink).
}

of operations (Rundell, 2006), and that these evacuees represent a disproportionally high proportion of those presenting for mental health care (Felker, Hawkins, Dobie, Gutierrez \& McFall, 2008).

Trauma and its psychological sequelae are highly prevalent in the general female population (Breslau, Kessler, Chilcoat, Schultz, Davis and Andreski, 1998). Although lifetime prevalence of exposure to any traumatic event has been observed to be higher among men (Breslau et al., 1998), epidemiologic studies such as the National Comorbidity Survey show that women are more likely than men to develop posttraumatic stress disorder (PTSD) after trauma exposure (Breslau, 2009; Breslau \& Davis, 1992; Bromet, Sonnega \& Kessler, 1998; Helzer, Robins \& McEvoy, 1987; Kessler, Sonnega, Bromet, Hughes \& Nelson, 1995). Importantly, the OEF/OIF conflicts are unique in that, for the first time, females are serving in combat alongside men in every capacity (Katz, Bloor, Cojucar \& Draper, 2007), thus increasing their exposure to trauma and risk for developing PTSD. A review of the literature supports that within the VA, PTSD may be under-diagnosed among female as compared to male veterans (Grossman, Willer, Stovall, McRae, Maxwell and Nelson, 1997; Pereira, 2002; SuffolettaMaierle, Grubaugh, Magruder, Monnier \& Frueh, 2003; Willer \& Grossman, 1995), even when female veterans report similar or higher levels of trauma exposure (Willer \& Grossman, 1995).

PTSD often co-occurs with other mental health disorders and problematic behaviors, including substance misuse (Dobie, Kivlahan, Maynard, Bush, Davis and Bradley, 2004; Stewart, 1996; Walker, Howard, Anderson, Walker, Lambert, Suchinsky et al., 1995). There is a paucity of research regarding substance use among women patients 
in the VA healthcare system (Davis et al., 2003). Extant literature suggests that female veterans receiving care at VA facilities are underdiagnosed in this area as well (Grossman et al., 1997; Willer \& Grossman, 1995), and are less likely to access or receive related clinical services to treat substance abuse (Hoff \& Rosenheck, 1997). Furthermore, research suggests that substance-abuse treatment is one type of mental health care that women in general seek out less frequently (Alexander, 1996; Weisner \& Schmidt, 1992), possibly because they attribute difficulties stemming from alcohol to the areas of health or mental health rather than viewing them as explicitly alcohol-related (Alexander, 1996).

Previous research has identified that female veterans screening positive for PTSD have significantly greater self-reported substance abuse when compared to women screening negative for PTSD (Dobie et al., 2004). To our knowledge, no one has examined this pattern of comorbidity in female veterans of the OEF/OIF conflicts. The objective of this study was to examine the rates of comorbid PTSD and substance abuse in an all-female OEF/OIF veteran sample, and to investigate differences in substance use in women screening positive versus those screening negative for PTSD.

\section{Method}

\subsection{Study population}

This study was part of a larger project evaluating mental and physical health in veterans newly enrolling for healthcare at a southern California VA medical center. From April to October of 2006, all veterans who presented to member enrollment for initial registration in the VA healthcare system were approached and asked to complete a paper-and-pencil battery of questionnaires. Veterans were enrolling in the general VA healthcare system, which includes primary healthcare, mental healthcare, and other VA-linked services. In all, 449 individuals agreed to participate; it is unknown how many who were initially approached declined. Of the 449 participants, 50 (11\%) were women, and of these, $36(8 \%)$ provided sufficient data for inclusion. The remainder $(N=14)$ was excluded from analyses due to greater than $25 \%$ missing data on: the PTSD, alcohol or drug use screening measures. This study was approved by the University of California, San Diego Institutional Review Board and the VA San Diego Healthcare System's Research and Development Committee.

\subsection{Data source}

\subsubsection{Demographics}

Participants completed a demographic background questionnaire, which provided data on age, gender, ethnicity, rank, branch of service (Air Force, Army, Marines, National Guard, Navy) and discharge type (General under honorable conditions, Honorable, Medical, Retired). Two single-item questions were intended as screening items to aid in describing the sample, and asked, "Did your military experience include exposure to combat" and "Were you ever treated for problems with alcohol" with response options yes/no.

\subsubsection{Standardized instruments}

The well-validated Alcohol Use Disorders Identification Test (AUDIT; (Saunders, Babor, de la Fuente \& Grant, 1993)) was used to screen for alcohol problems. The full 10 -item version was utilized, given that at identical cut-points, the standard 10-item AUDIT was more sensitive than the standard AUDIT-C for identifying past-year hazardous drinking and or DSM-IV alcohol abuse or dependence in a female veteran sample (Bradley, Bush, Epler, Dobie, Davis, Sporleder et al., 2003). Sample items from this measure include: "How often do you have a drink containing alcohol?" "How many drinks containing alcohol do you have on a typical day when you are drinking?" and "Has a relative, friend, doctor or other health worker been concerned about your drinking or suggested you cut down?" Response options vary by question, and often include frequency ("never" to "daily or almost daily") and severity (" 1 or 2 " to "10 or more" drinks). The timeframe referenced was the past 12 months. Scores were calculated in the standard manner by summing the scores for the 10 AUDIT questions, with possible scores ranging from 0 to 40 . For purposes of describing rates of high-risk drinking observed within our sample, a cut point on the AUDIT of greater than or equal to 3 was utilized, as this cutoff has been suggested for the female veteran affairs patient population, yielding a sensitivity of 0.70 and specificity of 0.86 (Bradley et al., 2003). For the main analysis, the AUDIT was left as a continuous variable. The Drug Abuse Screening Test-10 (DAST; (Maisto, Carey, Gordon \& Gleason, 2000)), a frequently employed and psychometrically sound screen for drug problems was also included. The original DAST is comprised of 28 items, however, a shorter 10-item version has demonstrated sufficiently robust psychometric properties, including the ability to differentiate among those who currently, formerly or never abused/were dependent on drugs and correlates as expected with other alcohol, drug and psychiatric indices (Cocco \& Carey, 1998). Sample items include the following, "Have you used drugs other than those required for medical reasons?" and "Do you ever feel bad or guilty about your drug use?" Response options include simple "yes" or "no" format. All questions refer to a past 12-month timeframe. Scores can range from 0 to 10 . A cutoff score of greater than or equal to 3 was instituted to identify participants with drug abuse and/or dependence as part of the descriptive data for our sample. This score has been identified as a "moderate level" of drug abuse problem and has demonstrated an acceptable level of sensitivity and specificity in both male and female participants (Bohn, Babor \& Kranzler, 1991; Cocco \& Carey, 1998). The DAST scores were left continuous for the main analysis. The Davidson Trauma Scale (DTS; (Davidson, Book, Colket, Tupler, Roth, David et al., 1997a; Wells, Macleod and Carroll, 2003)) was used to measure PTSD symptomatology. The DTS is a 17-item scale that assesses frequency and severity of trauma-related symptoms based on the DSM-IV PTSD criteria (APA, 2000). Sample questions include, "Have you ever had painful images, memories or thoughts of the event?", "Have you been avoiding any thoughts or feelings about the event?" and "Have you had trouble falling asleep or staying asleep?" Response options include "not at all" to "everyday" for frequency and "not at all distressing" to "extremely distressing" for severity. Participants were first asked to identify in writing the trauma that was "most disturbing" to them, and then to complete the DTS by endorsing frequency and severity of trauma-related symptoms in the "last week". Scores on the DTS can range from 0 to 136 . It is important to note that this measure does not provide a diagnosis of PTSD, but rather is reflective of current PTSD symptoms. A positive screen for PTSD was defined as a DTS cumulative score of greater than or equal to 40, a negative screen was defined as less than 40 (Davidson, Book, Colket, Tupler, Roth, David, Hertzberg, Mellman, Beckham, Smith, Davison et al., 1997b). The DTS was dichotomized in this manner in the main analysis.

\subsection{Data analysis}

Data analysis was performed using SPSS v.16.0. Initial analyses examined differences between participants who completed the assessment and those who did not using chi-square and t-tests for discrete and continuous variables, respectively. Descriptive statistics were computed to characterize the participants. Demographic variables between participants screening positive and negative for PTSD were then analyzed with chi-square tests including Yates' Correction for Continuity (categorical) and t-tests (continuous variables). This was done in order to identify any potential confounding variables that might need to be controlled for in the main analysis. Finally, a binary logistic regression utilizing AUDIT and 
DAST scores was conducted to predict membership into the PTSD group.

\section{Results}

\subsection{Characteristics}

Initial analyses indicated that those with complete data sets did not significantly differ from those with incomplete data sets on the following variables (where information was provided): age, exposure to combat, rank, branch of service, discharge type and ethnicity ( $\chi^{2}$ and $t \geq 0.05$ for discrete and continuous variables respectively). The sample of $36 \mathrm{OEF} / \mathrm{OIF}$ female veterans was young $(\mathrm{Md}=27.00$; $M=29.67$ years, $\mathrm{SD}=9.59$ ) and primarily Caucasian $(42 \%)$, Hispanic (25\%), or African-American (19\%). Most (83\%) had previously held ranks in mid-level enlisted positions, indicating some leadership responsibility (E-4 to E-6), and had been enrolled in the Navy (42\%), Marines (19\%), or Army (25\%). Importantly, only 2 (5.6\%) were ever treated for problems with alcohol and nearly all (92\%) reported being exposed to combat (see Table 1). Although nearly all endorsed combat-exposure, only 16 reported having ever experienced a "traumatic event", and thus provided DTS data; 20 endorsed no trauma. Of those 16 , only 12 provided a written description of their "most disturbing" trauma: 6 identified a single combat-related event, 2 identified a single medical problem (cardiac event and miscarriage), and 4 listed more than one trauma event with 2 of these reporting combat among the multiple events listed (sexual assault, child abuse, sudden unexpected death of loved one, suicide of a loved one, and car accident).

\subsection{PTSD and substance misuse}

Of the 36 participants, 11 (31\%) screened positive for PTSD, 17 (47\%) screened positive for high-risk drinking and 2 (6\%) screened positive for drug abuse.

Table 1

Demographic characteristics of participants $(N=36)$.

\begin{tabular}{|c|c|c|}
\hline Characteristic & $n$ & $\%$ \\
\hline \multicolumn{3}{|l|}{ Age at time of survey (years) } \\
\hline $20-25$ & 15 & 41.7 \\
\hline $26-30$ & 11 & 30.7 \\
\hline $31-40$ & 7 & 19.5 \\
\hline $40-65$ & 3 & 8.4 \\
\hline \multicolumn{3}{|l|}{ Ethnicity } \\
\hline Caucasian & 15 & 41.7 \\
\hline African-American & 7 & 19.4 \\
\hline Asian-American/Pacific Islander & 4 & 11.1 \\
\hline Hispanic & 9 & 25 \\
\hline Other & 1 & 2.8 \\
\hline \multicolumn{3}{|l|}{ Exposure to combat } \\
\hline Yes & 33 & 91.7 \\
\hline No & 3 & 8.3 \\
\hline \multicolumn{3}{|l|}{ Branch of service during $\mathrm{OEF} / \mathrm{OIF}$} \\
\hline Air Force & 2 & 5.6 \\
\hline Army & 9 & 25.0 \\
\hline Marines & 7 & 19.4 \\
\hline National Guard & 2 & 5.6 \\
\hline Navy & 15 & 41.7 \\
\hline \multicolumn{3}{|l|}{ Most recent discharge type } \\
\hline Honorable & 23 & 63.9 \\
\hline General under honorable conditions & 2 & 5.6 \\
\hline Retired & 4 & 11.1 \\
\hline Medical & 1 & 2.8 \\
\hline \multicolumn{3}{|l|}{ Previous treatment for alcohol problems } \\
\hline Yes & 2 & 5.6 \\
\hline No & 33 & 91.7 \\
\hline
\end{tabular}

3.3. Comparison of substance use in those screening positive versus negative for PTSD

The two groups did not differ significantly on any demographic variable, including: age, race, rank, exposure to combat, discharge type or branch enrolled ( $p>0.05, \chi^{2}$ and $t$-tests, respectively). A binary logistic regression using AUDIT and DAST scores to predict PTSD status (positive or negative) was conducted; variables were entered into the model in a forced entry fashion. This analysis yielded an overall model that was significant $\chi^{2}(2, N=36)=12.60, p \leq 0.01$. Table 2 provides a summary of this analysis; only alcohol misuse was significant in explaining unique variance in PTSD status. There was a significant effect for PTSD status, $t(11.13)=-2.33, p<0.05$, with those screening positive for PTSD having higher AUDIT scores ( $M d=4.00, M=6.55$, $\mathrm{SD}=6.06$ ) than those screening negative for PTSD ( $M d=1.00$, $M=2.18, \mathrm{SD}=2.15$ ). The overall correct classification rate for the binary logistic regression model was good, with $81 \%$ accuracy (Table 3 ). As an extension of these analyses, a linear regression using PTSD status (positive or negative) to predict AUDIT scores was conducted. PTSD status significantly predicted AUDIT scores, $\beta=0.48, t(34)=3.22$, $p<0.01$. PTSD status also explained a significant proportion of variance in AUDIT scores, $R^{2}=0.21, F(1,34)=10.37, p<0.01$.

\section{Discussion}

This study found that at a single VA Medical Center, a large percentage $(N=11 ; 31 \%)$ of a small sample of OEF/OIF female veterans presenting to member services for initial enrollment screened positive for PTSD symptoms. The proportion of women versus men (50 out of 449 respectively; $11 \%$ ) who presented to member services for enrollment in this study is similar to other studies examining OEF/OIF populations (Seal, Bertenthal, Miner, Sen \& Marmar, 2007). Additionally, almost half $(N=17 ; 47 \%)$ of the total sample of women had a positive screen for high-risk drinking behaviors, yet only 2 (5.6\%) participants had ever sought treatment for alcohol-related problems. Only two (6\%) of the 36 women screened positive for drug abuse. These findings corroborate past research that suggests a high percentage of problem drinking with female veterans from other eras (Davis et al., 2003). Alcohol and drug use were both good predictors of PTSD symptomatology, however, only problem drinking behaviors explained unique variance in the model. Additionally, it appears that the association between alcohol misuse and PTSD status is bi-directional; those screening positive for PTSD are more likely to report alcohol misuse and those with alcohol misuse are more likely to screen positive for PTSD. Although not unique to women, this finding supports previous studies suggesting that women with PTSD are more likely to have substance-related disorders such as alcohol abuse (Davis et al., 2003; Dobie et al., 2004).

A strength of this study is that it is the first, to the authors' knowledge, to investigate rates of PTSD and comorbid substancerelated disorders in an all-female OEF/OIF veteran population. Given the low rates of engagement in alcohol treatment among these combat-exposed women recently registered at the VA, these findings may highlight an unmet need for women recently separated from military service. Limitations include the following: first, the sample of women who presented for enrollment into VA services during the time of data collection is small, limiting the generalizability to all-

Table 2

Summary of logistic regression analysis predicting PTSD symptom status.

\begin{tabular}{lllll}
\hline Variable & $B$ & SE & Odds ratio & Wald statistic \\
\hline Alcohol misuse & 0.283 & 0.142 & 1.33 & $4.01^{*}$ \\
Drug misuse & 1.30 & 0.78 & 3.67 & 2.78 \\
\hline
\end{tabular}

* $p \leq 0.05$. 
Table 3

Accuracy of classification model.

\begin{tabular}{llll}
\hline Observed & Predicted & $\begin{array}{l}\text { Percentage } \\
\text { correct }\end{array}$ \\
\cline { 2 - 3 } & Negative PTSD screen & Positive PTSD screen \\
\hline Negative PTSD screen & 24 & 1 & $96 \%$ \\
Positive PTSD screen & 6 & 5 & $46 \%$ \\
Overall percentage & & & $81 \%$ \\
\hline
\end{tabular}

female OEF/OIF veterans including those who do not receive services within the VA. Indeed, to some degree, all registering veterans represent a self-selected, potentially treatment-seeking sample. Additionally, data were gathered through self-report measures as opposed to clinical interviews. Results may have differed if diagnostic interviews were included as part of the data collection procedures. Finally, our study was limited in that we did not have data on the alcohol usage for participants prior to their identified trauma. Thus, this study is not suggesting a causal relationship between PTSD symptom onset and alcohol problems, but rather, is hoping to highlight that female OEF/OIF veterans registering for care at VA facilities are presenting with high rates of PTSD and alcohol problems.

Women represent a rapidly growing (Goldberg, 2008) and high PTSD-risk (Felker et al., 2008) segment of the U.S. veteran population. Given the larger percentage of women serving in Iraq and Afghanistan conflicts as compared to past wars, it is expected that increasing numbers of women will be subjected to the hardships of a war zone deployment, including exposure to combat and other challenges associated with military service. In fact, this study found that the majority of our all-female sample (92\%) reported exposure to combat. With increased exposure to potentially traumatic events comes the concomitant risk of developing PTSD; the cumulative effect of trauma and greater symptom burden for survivors of multiple trauma events has recently been highlighted (Follette, Polusny, Bechtle \& Naugle, 1996; Suliman, Mkabile, Fincham, Ahmed, Stein and Seedat, 2009). Although our study did not limit the trauma-type to combat only, of the 16 participants endorsing trauma, 8 (50\%) listed combat as the single traumatic event or as one of several traumatic events linked to DTS symptom scores. This and previous research has suggested that female veterans presenting to the VA for treatment have high rates of PTSD (Suffoletta-Maierle et al., 2003). Since women who seek care at the VA may be under-diagnosed with PTSD and comorbid substance-related disorders (Grossman et al., 1997), an increased awareness of and screening for these issues in our female veterans is paramount.

In conclusion, gaps exist in our knowledge of female veterans struggling with PTSD, and we know little regarding how OEF/OIF veterans with psychiatric conditions are faring. Our findings suggest that mental health providers are likely to see high rates of PTSD and alcohol use disorders among women presenting at VA facilities for treatment. The VA is enrolling historically high rates of $\mathrm{OEF} / \mathrm{OIF}$ veterans compared to other war eras (Seal et al., 2007) and is continuing efforts to encourage women to seek services at VA facilities (Stecker, Han, Curran \& Booth, 2007). Accurate estimates of psychiatric conditions in female OEF/OIF veterans and valid diagnosis are essential to understanding the needs of female veterans. Further research in these areas will inform decisions regarding ideal delivery of medical services, which might include gender-specific substanceabuse groups (Alexander, 1996; Hoff \& Rosenheck, 1997), and assist in identifying which services will likely be in greater demand in the near future.

\section{Role of Funding Source}

Dewleen Baker is supported in part by the VA Research Grants: Merit (MERIT VA 1/041/08), HSR\&D (DHI07054 VA FY-08; \#PT074431 CDMRP 6/08-6/12; SDR 07-326 VA 7/077/08) and Cooperative Studies (CSP\# 504 VA 6/06-6/09; CSP\# 519 VA 10/04-10/09). All authors are supported, in part, by the VA Center of Excellence for Stress and Mental Health. The funding sources had no role in the study design, collection, analysis, interpretation of data, writing of the manuscript, or decision to submit for publication.

\section{Contributors}

Dewleen Baker, Pia Heppner, and Sarah Nunnink designed the study and wrote the protocol. Sarah Nunnink, Pia Heppner, Gali Goldwaser, and James Pittman conducted searches and provided a summary of previous research. Sarah Nunnink, Pia Heppner Gali Goldwaser and Caroline Nievergelt conducted the statistical analysis. All authors contributed to drafting the paper and approved the final draft.

\section{Conflict of Interest}

None for any author.

\section{Acknowledgements}

The authors acknowledge Mr. Clay King, MSW, Mr. Michael Kilmer, CMSW and Mr. Glenn White and his staff at the VA San Diego Healthcare System Member Services Department for their efforts in support of this project. The authors also acknowledge our funding sources, including VA Center of Excellence for Stress and Mental Health and VA Research Grants (Merit, HSR\&D and Cooperative Studies).

\section{References}

Alexander, M. J. (1996). Women with co-occurring addictive and mental disorders: An emerging profile of vulnerability. The American Journal of Orthopsychiatry, 66(1), $61-70$.

APA. (2000). Diagnostic and statistical manual of mental disorders, fourth edition, text revision. Arlington, VA: American Psychiatric Association.

Bohn, M. J., Babor, T. F., \& Kranzler, H. R. (1991). Validity of the Drug Abuse Screening Test (DAST-10) in inpatient substance abusers. Problems of Drug Dependence, 119, $233-235$.

Bradley, K. A., Bush, K. R., Epler, A. J., Dobie, D. J., Davis, T. M., Sporleder, J. L., et al. (2003) Two brief alcohol-screening tests from the Alcohol Use Disorders Identification Test (AUDIT): Validation in a female Veterans Affairs patient population. Archives of Internal Medicine, 163(7), 821-829.

Breslau, N. (2009). The epidemiology of trauma, PTSD, and other posttrauma disorders. Trauma Violence Abuse, 10(3), 198-210.

Breslau, N., \& Davis, G. C. (1992). Posttraumatic stress disorder in an urban population of young adults: Risk factors for chronicity. The American Journal of Psychiatry, 149 (5), 671-675.

Breslau, N., Kessler, R. C., Chilcoat, H. D., Schultz, L. R., Davis, G. C., \& Andreski, P. (1998). Trauma and posttraumatic stress disorder in the community: The 1996 Detroit Area Survey of Trauma. Archives of General Psychiatry, 55(7), 626-632.

Bromet, E., Sonnega, A., \& Kessler, R. C. (1998). Risk factors for DSM-III-R posttraumatic stress disorder: Findings from the National Comorbidity Survey. American Journal of Epidemiology, 147(4), 353-361.

Cocco, K. M., \& Carey, K. B. (1998). Psychometric properties of the drug abuse screening test in psychiatric outpatients. Psychological Assessment, 10(4), 408-414.

Davidson, J. R., Book, S. W., Colket, J. T., Tupler, L. A., Roth, S., David, D., et al. (1997) Assessment of a new self-rating scale for post-traumatic stress disorder. Psychological Medicine, 27(1), 153-160.

Davidson, J. R., Book, S. w., Colket, J. T., Tupler, L. A., Roth, S., David, D., et al. (1997) Assessment of a new self-rating scale for post-traumatic stress disorder. Psychological Medicine, 27(1), 153-160.

Davis, T. M., Bush, K. R., Kivlahan, D. R., Dobie, D. J., \& Bradley, K. A. (2003). Screening for substance abuse and psychiatric disorders among women patients in a VA Health Care System. Psychiatric Services, 54(2), 214-218.

Dobie, D. J., Kivlahan, D. R., Maynard, C., Bush, K. R., Davis, T. M., \& Bradley, K. A. (2004) Posttraumatic stress disorder in female veterans: Association with self-reported health problems and functional impairment. Archives of Internal Medicine, 164(4), 394-400.

DOD (2008). Active duty military personnel by rank and grade: September 30, 2008 (women only). 2008. Retrieved September 4, 2009, 2009, from the Department of Defense: http://siadapp.dmdc.osd.mil/personnel/MILITARY/rg0809f.pdf

DVA (2007). Table 5L: Veterans $2000-2036$ by race/ethnicity, gender, period, age [data file], from the Department of Veterans Affairs: http://www1.va.gov/vetdata/page. cfm?pg $=15$

Felker, B., Hawkins, E., Dobie, D., Gutierrez, J., \& McFall, M. (2008). Characteristics of deployed Operation Iraqi Freedom military personnel who seek mental health care. Military Medicine, 173(2), 155-158.

Follette, V. M., Polusny, M. A., Bechtle, A. E., \& Naugle, A. E. (1996). Cumulative trauma: The impact of child sexual abuse, adult sexual assault, and spouse abuse. Journal of Traumatic Stress, 9(1), 25-35.

Goldberg, K. C. (2008). The epidemiology of health problems in returning Operation Iraqi Freedom and Operation Enduring Freedom veterans. A national and North Carolina-based summary. North Carolina Medical Journal, 69(1), 31-34.

Goldzweig, C. L., Balekian, T. M., Rolon, C., Yano, E. M., \& Shekelle, P. G. (2006). The state of women veterans' health research. Results of a systematic literature review. Journal of General Internal Medicine, 21(Suppl 3), S82-S92.

Grossman, L. S., Willer, J. K., Stovall, J. G., McRae, S. G., Maxwell, S., \& Nelson, R. (1997). Underdiagnosis of PTSD and substance use disorders in hospitalized female veterans. Psychiatric Services, 48(3), 393-395. 
Helzer, J. E., Robins, L. N., \& McEvoy, L. (1987). Post-traumatic stress disorder in the general population. Findings of the epidemiologic catchment area survey. The New England Journal of Medicine, 317(26), 1630-1634.

Hoff, R. A., \& Rosenheck, R. A. (1997). Utilization of mental health services by women in a male-dominated environment: The VA experience. Psychiatric Services, 48(11), $1408-1414$.

Katz, L., Bloor, L., Cojucar, G., \& Draper, T. (2007). Women who served in Iraq seeking mental health services: Relationships between military sexual trauma, symptoms, and readjustment. Psychological Services, 4(4), 239-249.

Kessler, R. C., Sonnega, A., Bromet, E., Hughes, M., \& Nelson, C. B. (1995). Posttraumatic stress disorder in the National Comorbidity Survey. Archives of General Psychiatry, 52(12), $1048-1060$.

Kussman, M. J. (2008). Uniform Mental Health Services in VA Medical Centers and Clinics. Retrieved September 4, 2009 from http://www1.va.gov/vhapublications ViewPublication.asp?pub ID $=1762$

Maisto, S. A., Carey, K. B., Gordon, C. M., \& Gleason, J. R. (2000). Use of the AUDIT and the DAST-10 to identify alcohol and drug use disorders among adults with a severe and persistent mental illness. Psychological Assessment, 12, 186-192.

Pereira, A. (2002). Combat trauma and the diagnosis of post-traumatic stress disorder in female and male veterans. Military Medicine, 167(1), 23-27.

Romeis, J. C., Gillespie, K. N., \& Thorman, K. E. (1988). Female veterans' use of health care services. Medical Care, 26(6), 589-595.

Rundell, J. R. (2006). Demographics of and diagnoses in Operation Enduring Freedom and Operation Iraqi Freedom personnel who were psychiatrically evacuated from the theater of operations. General Hospital Psychiatry, 28(4), 352-356.

Saunders, J. B., Babor, T. F., de la Fuente, J. R., \& Grant, M. (1993). Development of the Alcohol Use Disorders Identification Test (AUDIT): WHO collaborative project on early detection of persons with harmful alcohol consumption. Addiction, 88, $791-804$.

Seal, K. H., Bertenthal, D., Miner, C. R., Sen, S., \& Marmar, C. (2007). Bringing the war back home: Mental health disorders among 103,788 US veterans returning from
Iraq and Afghanistan seen at Department of Veterans Affairs facilities. Archives of Internal Medicine, 167(5), 476-482.

Stecker, T., Han, X., Curran, G. M., \& Booth, B. M. (2007). Characteristics of women seeking intensive outpatient substance use treatment in the VA. Journal of Women's Health (Larchmt), 16(10), 1478-1484.

Stewart, S. H. (1996). Alcohol abuse in individuals exposed to trauma: A critical review. Psychological Bulletin, 120(1), 83-112.

Suffoletta-Maierle, S. Grubaugh, A. L Magruder, K, Monnier, J. \& Frueh, B. C. (2003). Trauma-related mental health needs and service utilization among female veterans. Journal of Psychiatric Practice, 9(5), 367-375.

Suliman, S., Mkabile, S. G., Fincham, D. S., Ahmed, R., Stein, D. J., \& Seedat, S. (2009). Cumulative effect of multiple trauma on symptoms of posttraumatic stress disorder, anxiety, and depression in adolescents. Comprehensive Psychiatry, 50(2), 121-127.

Walker, R. D., Howard, M. O., Anderson, B., Walker, P. S., Lambert, M. D., Suchinsky, R., et al. (1995). Diagnosis and hospital readmission rates of female veterans with substance-related disorders. Psychiatric Services, 46(9), 932-937.

Weisner, C., \& Schmidt, L. (1992). Gender disparities in treatment for alcohol problems. The Journal of the American Medical Association, 268(14), 1872-1876.

Wells, J. W. T., Macleod, A., \& Carroll, G. (2003). Posttraumatic stress disorder: Do electrical startle responses and thyroid function usefully supplement self-report? A study of Vietnam War veterans. Australian and New Zealand Journal of Psychiatry, 37 (3), 334-339.

Willer, J. K., \& Grossman, L. S. (1995). Mental health care needs of female veterans. Psychiatric Services, 46(9), 938-940.

Yano, E. M., Bastian, L. A., Frayne, S. M., Howell, A. L., Lipson, L. R., McGlynn, G., et al. (2006). Toward a VA Women's Health Research Agenda: Setting evidence-based priorities to improve the health and health care of women veterans. Journal of General Internal Medicine, 21(Suppl 3), S93-S101. 